\title{
APRENDIZAGEM MUSICAL COLABORATIVA MEDIADA PELAS TECNOLOGIAS DIGITAIS: UMA PERSPECTIVA METODOLÓGICA PARA O ENSINO DE MÚSICA
}

Musical Collaborative Learning mediated by digital

technologies: a methodological perspective for teaching music

\author{
FRANCINE KEMMER CERNEV \\ Universidade de Brasília \\ francine@cernev.com.br
}

\begin{abstract}
Resumo: Neste ensaio, busco refletir sobre a importância da aprendizagem musical colaborativa no âmbito da educação musical, trazendo, a partir de uma perspectiva metodológica, discussões e problematizações sobre o emprego das tecnologias digitais nesses contextos. Inicialmente, discorro sobre princípios e visões propostas por autores que tratam do tema, evidenciando desafios e possibilidades de trabalhos desenvolvidos coletivamente. A seguir, apresento trabalhos específicos da educação musical, incluindo pesquisas e aspectos de minha experiência profissional dentro desta perspectiva. Coloco em evidência avanços e limites da área, tecendo considerações sobre o tema passiveis de suscitar questionamentos, abrir novos diálogos, bem como fomentar outros debates. Por fim, defendo que a aprendizagem musical colaborativa deve sempre estar calcada no respeito e na valorização dos interesses dos alunos e professores, a partir do contexto sociocultural de origem, fundamentada numa visão ampla, considerando práticas musicais, valores, conflitos e interesses diversos.
\end{abstract}

Palavras-chave: Aprendizagem colaborativa. Cooperação e colaboração. Tecnologias digitais.

\begin{abstract}
In this essay, I try to reflect on the importance of collaborative musical learning in the field of music education, bringing, from a methodological perspective, discussions and problematizations about digital technologies in these contexts. Initially, I discuss principles and perspectives proposed by authors that deal with the theme, highlighting the challenges and possibilities of working together. Next, I present specific works of music education, including research and aspects of my professional experience within this perspective. I highlight the advances and limits of the area by making considerations on the subject, which may raise questions, open new dialogues, and encourage other debates. Finally, I advocate that collaborative musical learning should always be based on respect and appreciation of the interests of students and teachers, based on the socio-cultural context of origin, based on a broad vision of learning, considering musical practices, values, conflicts and diverse interests.
\end{abstract}

Keywords: Collaborative learning. Cooperation \& collaboration. Digital technologies. 


\section{INTRODUÇÃO}

O uso das tecnologias digitais na aprendizagem musical colaborativa tem sido destaque em diversas áreas do conhecimento, gerando entre pesquisadores, diretores, professores e opinião pública uma série de discussões sobre suas potencialidades, criticas e possiveis limites em sala de aula (Cernev, 2017a). Observando essas questões, desde 2009 tenho desenvolvido uma série de estudos e participado de múltiplas experiências educativas no ensino superior e na educação básica que envolvem o uso das tecnologias digitais e práticas musicais em sala de aula (Cernev, 2013, 2015, 2016, 2017a, 2017b; Cernev; Malagutti, 2016; Cernev; Ribeiro; Cereser, 2015; Guerra; Cernev, 2017). Acima de qualquer inovação tecnológica, tenho pensado em como seu uso pode contribuir com as aulas de música, buscando não considerar apenas os benefícios do uso da tecnologia em si, mas suas potencialidades no desenvolvimento de uma aprendizagem musical crítica e participativa.

Os resultados desses estudos apontam para os beneficios da aprendizagem colaborativa em sala de aula, principalmente por abrir um espaço colaborativo para discussão, construção e formação do espírito crítico entre alunos e professores. No processo de formação de professores, por exemplo, retratam a realidade ocorrida entre os licenciandos em música utilizando as TIC e suas visões sobre este uso em suas futuras atuaç,ões docentes (Cernev, 2017a). Já na formação continuada, as tecnologias digitais associadas a um fazer pedagógico problematizado e colaborativo foram destaque para os professores criarem novas formas de pensar e agir profissionalmente (Guerra; Cernev, 2017).

Buscando entender como ocorre a colaboração no contexto da educação básica, realizei em meu doutorado uma pesquisa cujo objetivo foi investigar a motivação para aprender música colaborativamente utilizando as tecnologias digitais (Cernev, 2015, 2016). Esta pesquisa, desenvolvida no ensino fundamental II por meio da pesquisa-ação, retratou como ações colaborativas podem estabelecer trocas, partilhas e parcerias entre alunos e professores. Revelou, também, como uma proposta metodológica pautada na colaboração foi essencial para a construção da aprendizagem musical colaborativa em sala de aula.

Assim, com base em minhas experiências docentes, em meus estudos e em ampla revisão bibliográfica, busco, neste artigo, refletir sobre a aprendizagem musical colaborativa para o ensino de música, defendendo a articulação da discussão teórica e da prática que envolve o processo de ensino e aprendizagem na área da educação musical. Partindo da perspectiva defendida neste texto, a questão metodológica é assumida como discussão 
curricular $^{1}$, pois assume a importância da atuação direta dos alunos, seus estilos ou estratégias de aprendizagem e como determinados conhecimentos ganham significados e participam de processos a partir dos quais a música se relaciona com sua formação e sua identidade cultural.

Para tanto, primeiramente são apresentadas algumas definições e conceitos sobre colaboração e cooperação no âmbito educacional a partir de uma revisão de autores que têm buscado teorizar sobre essa temática. A seguir, discuto alguns trabalhos que envolvem a aprendizagem colaborativa utilizando as tecnologias digitais que, a partir da perspectivas dos autores pesquisados, contribuem significativamente para a mediação e interação no processo metodológico em sala de aula. Com essa mesma visão, evidencio alguns trabalhos acerca dessa temática na área da educação musical e discorro sobre as pesquisas desenvolvidas por mim e que fornecem a base para a construção de uma proposta metodológica para o ensino de música pautada na colaboração.

Este artigo não busca defender ou propor uma determinada abordagem metodológica, mas, sim evidenciar principios e recursos que emergem de diferentes possibilidades metodológicas para o uso das tecnologias digitais em sala de aula. O importante é que o tipo de abordagem e interação possa envolver o tipo de aprendizagem que o professor está propondo em suas aulas. Inevitavelmente, o que vai determinar a escolha de uma ou outra situação e proposta de ensino dependerá do nivel de preparo do professor para mediar tais ações e da construção dele com seus alunos para que tenham habilidade e maturidade para o desenvolvimento das diferentes situações de aprendizagem propostas pelas TIC. Tais questões também estão relacionadas às escolhas e familiaridades com que o professor se relaciona com as tecnologias digitais, uma vez que elas contribuem diretamente na mediação destas aprendizagens.

\section{DEFINIÇÃO DE COLABORAÇÃO E COOPERAÇÃO}

A expressão "aprendizagem colaborativa" tem sido utilizada em vários âmbitos das ciências humanas, tendo como premissa o desenvolvimento de um trabalho conjunto que visa um objetivo comum. Este tipo de aprendizagem também é conceituada a partir de outras definições, como: aprendizagem cooperativa, aprendizado coletivo, comunidades de aprendizagem, aprendizagem participativa, trabalho cooperativo, aprendizagem entre pares, aprendizado em equipe, entre outros. Em comum, todos eles focam a importância de um trabalho realizado em grupo. No entanto, especificidades são inerentes, uma vez que, por diferentes visões e perspectivas, tais processos de aprendizagem abordam distintas formas de interação no contexto educativo.

\footnotetext{
${ }^{1}$ Currículo aqui definido como relações sociais, culturais, políticas e administrativas que envolvem a criação e a produção de conhecimento (Gimeno Sacristán, 2000).
} 
No entender de alguns autores, a cooperação é vista como um processo de aprendizagem que visa o produto final, que propicia aos estudantes a discussão, o compartilhamento de ideias e o estabelecimento de normas com o intuito de realizar uma atividade. Muitas vezes tais atividades são divididas em subtarefas a serem desenvolvidas independentemente (Kagan; Kagan, 2009; Roschelle; Teasley, 1995).

Autores como Panitz (1999), Johnson, Johnson e Holubec (2008) e Li e Lam (2013) descrevem que o aprendizado cooperativo ocorre a partir de uma instrução do professor, que projeta estruturas de interação social, promove discussões e organiza o envolvimento dos alunos. A partir de então, eles assumem o papel e a responsabilidade por sua própria aprendizagem e pela aprendizagem de todos os membros do grupo. Os alunos interagem uns com os outros para adquirir e praticar as ações necessárias com o intuito de resolver um determinado problema, completar uma tarefa ou alcançar um objetivo. Dessa maneira, a cooperação é entendida como uma forma de interação em que os participantes realizam uma ação através da subdivisão do trabalho em partes (Kagan; Kagan, 2009; Li; Lam, 2013).

Esse tipo de ação coletiva é comum nos sistemas empresariais e muito utilizada em ambientes educacionais administrativos. Tais ações, iniciadas após a revolução industrial, surgiram com a premissa de romper com as gestões impositivas dos chefes a fim de propiciar melhores condições de trabalho. Atualmente, muitas organizações buscam desenvolver ambientes cooperativos, uma vez que funcionários comprometidos com o trabalho e a visão de sua empresa "cooperam mutuamente nas ações que requerem habilidades gerais e também específicas, havendo uma forte relação de confiança e parceria" (Rodrigues et al., 2011, p. 129). Esta visão de trabalho tem sido muito utilizada na educação privada e em algumas áreas das ciências sociais.

De acordo com Johnson, Johnson e Holubec (2008) e Li e Lam (2013), a base teórica da aprendizagem cooperativa está relacionada ao pensamento de Lev Semyonovic Vygotsky, que conceitua o desenvolvimento das habilidades, da linguagem e do raciocinio a partir da cultura. A perspectiva sociocultural do pensamento de Vygotsky ${ }^{2}$ discute que a aprendizagem ocorre e se estabelece nas relações sociais com pais, colegas e professores em seus distintos ambientes socioculturais.

O Boletim Informativo da Associação Internacional para o Estudo da Cooperação em Educação ${ }^{3}$ (International Association for the Study of Cooperation in Education) tem trazido constantemente estudos em publicações de artigos, livros e conferências sobre os benefícios da cooperação no ambiente educacional (melhores resultados na aprendizagem, grupos mais coesos e participativos e relacionamento interpessoal intensificado, entre

\footnotetext{
2 Para aprofundamento sobre essa temática, sugiro a leitura da obra: REGO, Teresa Cristina. Vygotsky: uma perspectiva histórico-cultural da educação. 20. ed. Petrópolis: Vozes, 2009.

${ }^{3}$ Disponível em: <http://www.iasce.net>.
} 
outros). No site dessa associação é possivel encontrar pesquisas que abordam o envolvimento e o desenvolvimento cooperativo no ensino superior, em grupos multiculturais, na aprendizagem dentro da construção da pesquisa científica e em propostas metodológicas para o ensino em diferentes campos das ciências humanas. É o caso, por exemplo, de uma revista específica sobre cooperação em educação (Myers, 2017), que apresenta uma série de contribuições para as práticas realizadas pelos alunos em diferentes estudos, e sobre a tese de Cangro (2004), que discute sobre a aprendizagem cooperativa em música.

O desenvolvimento de uma proposta educacional cooperativa tem como base, então, algumas características e envolve ações específicas. Partindo da concepção de que existe uma divisão clara de tarefas nesse tipo de experiência, cada membro do grupo assume uma responsabilidade específica e individual que deve ser cumprida para o sucesso do todo. Mesmo com divisão e ação individual entre os integrantes do grupo, existe a necessidade de compartilhamento constante com os demais participantes das ações promovidas individualmente. É importante destacar que, mesmo com a divisão de tarefas, numa aprendizagem que visa à cooperação, os objetivos, as metas, a avaliação e a forma de organização da atividade são sempre ações estabelecidas com todo o grupo.

Já a colaboração no ambiente educacional é constantemente associada à expressão aprendizagem colaborativa e empregada pelos educadores como uma prática necessária para desenvolver e fomentar o aprendizado em sala de aula (Cernev, 2015). A palavra colaboração, contudo, é utilizada para os mais diversos significados, de acordo com os objetivos educacionais de cada pesquisa. É comum observar na literatura da década de 1990 a busca de uma conceituação de colaboração sobre diversas perspectivas, concepções e ideologias.

Otsuka (1999) destaca que até o início de 1995 poucas pesquisas tinham como foco a aprendizagem colaborativa. $O$ interesse por esse tipo de situação de ensino surgiu na segunda metade dessa década devido às transformações sociais, às mudanças tecnológicas e às exigências do mercado de trabalho. Verdejo (1996, p. 80), por exemplo, abordou a colaboração como uma forma de interação que trouxe a "conversa ou paradigma dialógico" entre os participantes.

Roschelle e Teasley (1995) discorreram sobre a aprendizagem colaborativa como uma forma de interação "filosófica" em que esta fomentaria o pensamento crítico e o compartilhamento, a compreensão e a forte retenção da aprendizagem em longo prazo entre os estudantes. Otsuka (1999) destacou que a colaboração no ambiente educacional possui objetivos e metas específicas, dentre as quais, a promoção do desenvolvimento cognitivo e social em grupo, o estímulo ao pensamento crítico, discussões e reflexões dos alunos, a adoção da ideia de aprendizagem para a vida (lifelong learning), o 
aumento da autoestima, da afetividade e da motivação para as atividades educacionais.

Alguns autores defendem que a aprendizagem colaborativa e a aprendizagem cooperativa são distintas e se sobrepõem, enquanto outros as defendem como sinônimas ou mesmo equivalentes. É o caso, por exemplo, de estudos como os de Johnson e Johnson (1996) e Hiltz (1998), que acreditam que colaboração e cooperação são sinônimas, uma vez que em ambas estão presentes as possibilidades de interação e, por serem muito próximas, no ambiente educacional são consideradas como equivalentes. Já Brna (1998) discute que colaboração e cooperação são termos distintos e independentes, uma vez que a cooperação visa o processo na execução de uma atividade, enquanto a colaboração é uma concepção ideológica. Para o autor, é possivel em cada ação perceber diferentes tipos de relações entre os participantes.

A colaboração pode também ser vista como uma estratégia metodológica para a aprendizagem. É o caso de Bruffe (1993), que a abordou como uma estratégia para o professor utilizar em sala de aula, onde esta envolveria a autonomia dos alunos e a participação de todos no processo de produção de conhecimento. $\mathrm{O}$ autor diferenciou cooperação e colaboração no ambiente educacional, destacando que o processo de cooperação ocorre geralmente quando esse se faz sob o controle ou centralização do professor, enquanto a colaboração envolveria como eixo central o papel do aluno. Torres, Alcântara e Irala (2004) relataram em suas pesquisas essa visão de colaboração e cooperação, buscando na primeira uma estratégia para o desenvolvimento da autonomia dos alunos em idade escolar.

Sob esta visão, a colaboração envolve todo o processo de ensino, não apenas suas metas e resultados. Também, tendo sua contribuição com a perspectiva construtivista de Vygostky, outros teóricos, como Palincsar (1998) e Flynn et al. (2013), trazem fundamentos para definição do conceito de aprendizagem colaborativa. Para tais teóricos, a colaboração é concebida como uma forma de interação entre os participantes que buscam desenvolver uma ação conjuntamente em todas as fases do processo de construção do conhecimento.

Autores que teorizam sobre a aprendizagem colaborativa descrevem a importância não apenas dos alunos no processo de partilha e construção do conhecimento, como também o papel do professor nesse aprendizado, num esforço comum para a construção e produção do conhecimento, modificando, assim, a natureza da sala de aula. Desta forma, ao contrário do aprendizado cooperativo, onde o foco é trabalhar em conjunto e requer uma interdependência, na colaboração, o foco é trabalhar uns com os outros (mas não necessariamente interdependentemente) em direção ao mesmo objetivo com a mesma ação, na busca comum de descoberta, compreensão ou produção de conhecimento (Cernev, 2015; Davidson; Major, 2014).

Entender esta perspectiva metodológica de aprendizagem fomenta algumas considerações: os alunos aprendem com o professor, mas não 
necessariamente só por meio dele; eles também aprendem com colegas e aprendem buscando em grupo o conhecimento em diferentes situações (livros, apostilas, internet, profissionais, comunidade etc.). Quando percebem que possuem ou adquirem um determinado conhecimento ou habilidade, esses alunos ensinam aos seus colegas e também ao seu professor. Isso significa que todos são responsáveis por sua própria aprendizagem e pela aprendizagem de todo o grupo. Desta forma, o ensino torna-se uma transação entre todos os intervenientes no processo educativo.

Os estudos de Pierce e Gilles (2008) e Barnes (2008) destacam algumas ações e estratégias para propiciar a aprendizagem colaborativa no contexto educacional. Barnes (2008) destaca a roda de conversas (de forma exploratória) a fim de criar conexões, exemplos e hipóteses entre os alunos. Para o autor, é importante que eles criem perguntas e busquem possiveis soluções e respostas. Tais perguntas servem não apenas para o pensamento produtivo do grupo, mas para fornecer informações ao professor sobre o nivel de compreensão que os alunos estão apresentando sobre um determinado assunto e assim contribuir para fomentar visões criticas e aprofundadas entre todos.

Pierce e Gilles (2008) aprofundam o tema e discutem diferentes categorias para fomentar as discussões colaborativas em sala de aula. Para os autores, devem existir momentos para o desenvolvimento de conversas sociais, conversas exploratórias, conversas de apresentação e conversas críticas. Segundo eles, não existem momentos específicos para cada tipo de conversa, uma vez que elas ocorrem simultaneamente e interdependentemente. O que importa é propiciar e fomentar tais discussões, sempre em busca de criar ações e provocar mudanças.

Segundo Davidson e Major (2014), a cooperação tem sido a escolha principal das pesquisas desenvolvidas no cenário educacional, muitas vezes pela dificuldade do professor em descentralizar seu próprio papel na construção do conhecimento. Os autores discutem também que ambas as aprendizagens propõem o engajamento ativo, o aprendizado em grupo e o desenvolvimento das capacidades de pensamento entre os alunos. Destacam, também, metas semelhantes a serem utilizadas pelos professores no processo de ensino e a aprendizagem a fim de incentivar o desenvolvimento do conhecimento de conteúdos e habilidades relacionadas, mesmo que existam diferenças de metodologia.

\section{APRENDIZAGEM MUSICAL COLABORATIVA E AS TECNOLOGIAS DIGITAIS}

A aprendizagem musical colaborativa numa perspectiva metodológica remete a movimentos do pensamento e a um conjunto de procedimentos a partir dos quais se pode levar a produção do conhecimento em música. Tratase, portanto, de uma perspectiva que não pode prescindir de uma base teórica 
e que requer do professor de música um investimento intelectual que suplante o movimento de busca de inovações em torno de sua prática musical já consolidada (Cernev, 2015, 2017a). Por essa razão, tem como foco o professor como autor e pesquisador do seu conhecimento, e não um técnico meramente transmissor de conteúdos e procedimentos.

O uso das tecnologias digitais no ambiente educacional tem suscitado a necessidade da formação de professores para que se adaptem aos atuais contextos de ensino. É fato que as tecnologias digitais podem auxiliar na interação e na colaboração em sala de aula e desempenham um papel de destaque em todos os setores da educação (Moran, 2013; Serres, 2012; Mattar, 2010; Silva, 2010). Com o advento das tecnologias digitais e sua construção dentro do processo educativo, uma série de estudos tem abordado sua importância na vida acadêmica, tais como a possibilidade de relacionamento e participação dos alunos em atividades escolares utilizando a internet (Drotner, 2008; Boyd; Ellison, 2007; Capellini, 2004) ou o uso de redes sociais como o Facebook e o YouTube (Barnes; Marateo; Ferris, 2007; Cernev, 2017a; Fisher; Baird, 2005). Outros discutem as tendências disponibilizadas pelas inovações tecnológicas que podem auxiliar o professor em suas atividades acadêmicas (Harasim, 2017; Stahl, 2009; Koschmann, 2002) ou contribuir com a aprendizagem em sala de aula (Jenkins, 2006, Cernev, 2013).

Nas investigações sobre a aprendizagem colaborativa que utiliza as tecnologias digitais, os resultados têm revelado os beneficios tanto para alunos como professores quando estes se envolvem de forma ativa no processo de construção do conhecimento. Nesse sentido, Greiffenhagen (2012) investigou as ações pedagógicas dos professores durante o desenvolvimento de atividades colaborativas em sala de aula usando a tecnologia digital. $\mathrm{O}$ autor abordou os limites da interação estabelecida entre os alunos e o professor, uma vez que, por mais que este interaja com os alunos buscando uma aproximação de igualdade, as perspectivas podem variar e se entrelaçar em diferentes atividades. Este fato ocorre porque, segundo o autor, o professor busca ensinar o conhecimento em sala de aula enquanto os alunos tentam descobrir o conhecimento por conta própria, explorando o ciberespaço.

Drotner (2008), Boyd e Ellison (2007) e Jenkins (2006) discutiram a importância do uso das tecnologias digitais no ambiente escolar e relataram que as escolas muitas vezes restringem seu uso nos espaços acadêmicos por meio de bloqueios a sites, ferramentas de comunicação e redes sociais, argumentando que tais ações fazem com que os jovens tenham cada vez menos interesse pela escola e pelas atividades acadêmicas. Os três estudos enfatizaram que as escolas estão perdendo ricas oportunidades na construção crítica do conhecimento colaborativo em sala de aula, além da oportunidade de discutir com os alunos os aspectos positivos e negativos de como as tecnologias diferem das formas mais tradicionais de expressão e informação. 
As pesquisas realizadas no Brasil na área musical mostram a importância da aprendizagem colaborativa no contexto da educação musical. Com o advento do ciberespaço, os avanços tecnológicos e mercadológicos criaram novas tendências para músicos, compositores e estudantes (Hentschke; Schneider; Cernev, 2012; Moura, 2010; Gohn, 2008). Nesse sentido, Gohn (2013) discute alguns caminhos para o ensino de música na modalidade a distância, e Moura (2010) aborda como o uso das TIC pode contribuir para uma abordagem de colaboração. A autora defende um currículo de formação de professores que contemple práticas para acesso e domínio das tecnologias da informação auxiliando na ampliação de práticas musicais escolares condizentes com as realidades encontradas em sala de aula.

Hentschke, Schneider e Cernev (2012, 2011) investigaram os processos pedagógicos musicais na implantação de uma proposta de ensino utilizando as tecnologias digitais para as séries finais da educação básica. Valendo-se de material didático próprio, as autoras puderam avaliar a compreensão dos professores e alunos quanto ao conteúdo gerado e analisaram a relação entre o uso das tecnologias digitais e a motivação para aprender e ensinar música em quatro diferentes ambientes de ensino (municipal, estadual, particular e projeto sociocultural). Os resultados apontaram beneficios para alunos e professores em todos os ambientes, tanto para o desenvolvimento das atividades musicais quanto para a potencialidade do uso das TIC. Como benefícios, as autoras assinalaram o uso das tecnologias digitais livres como ferramenta para aproximar as aulas de música ao cotidiano em sala de aula, bem como para o desenvolvimento de trabalhos colaborativos e uma consequente motivação para aprender música.

Burnard (2007) investigou como as tecnologias poderiam contribuir em práticas musicais criativas em aulas de música. Os resultados mostraram que o uso destas tecnologias facilita a aprendizagem tanto para os alunos quanto para os professores, que tiveram a possibilidade de aprender com alunos mais esclarecidos em tecnologias digitais. Tais aspectos evidenciam a importância da colaboração no processo de aprendizagem musical e destacam a importância das tecnologias dando suporte para novas propostas metodológicas de ensino, contribuindo no aprendizado dos alunos e empregando ferramentas de uso comum.

O estudo de Burnard (2007) mostra resultados positivos no que se refere à implementação da colaboração no ambiente acadêmico escolar. O primeiro deles se refere aos tipos de interações e colaborações estabelecidas em sala de aula. O segundo refere-se às novas práticas pedagógicas utilizadas pelos professores, que mudaram os paradigmas de ensino e aprendizagem no dia a dia escolar. Nesse estudo foi possivel discutir a troca de conhecimentos e de pontos de vistas entre os alunos durante as atividades musicais, potencializando a tomada de decisões de forma clara e objetiva pelos professores, o que contribuiu para uma maior motivação dos mesmos. 


\section{APRENDIZAGEM MUSICAL COLABORATIVA: UMA PROPOSTA METODOLÓGICA}

Nos estudos que tenho realizado, bem como a partir de minhas experiências profissionais, tenho centrado minhas discussões sobre a importância da aprendizagem colaborativa no processo de construção do conhecimento musical e no papel do professor em compreender e transformar sua atuação profissional numa busca constante de descoberta, compreensão e produção de conhecimento.

Com base na proposta metodológica desenvolvida em meu doutorado (Cernev, 2015) e em estudos posteriores (Cernev, 2016, 2017a, 2017b), entendo que, ao fomentar a colaboração nas aulas de música, as atividades que buscam novos caminhos e práticas pedagógicas auxiliam os alunos a criarem suas próprias estratégias de aprendizagem. As aulas, delineadas sempre de forma aberta ${ }^{4}$, possibilitam que eles elaborem e concretizem seus projetos de acordo com seus interesses pessoais e, também, com base em negociações que fazem com seus colegas e professores.

Para tanto, é necessário propor uma metodologia em que os alunos possam se tornar "atores e autores" de sua própria aprendizagem, partindo da concepção interacionista e construtivista do conhecimento.

Desta forma, priorizando coerência com os objetivos educacionais e comprometidas com uma educação musical de qualidade, as atividades devem envolver constantemente reflexões sobre o planejamento, o desenvolvimento e a avaliação da aprendizagem destes alunos em sala de aula.

Em minha tese de doutorado (Cernev, 2015), desenvolvi uma metodologia em que, a cada situação de aprendizagem, os alunos eram instigados a escolher os conteúdos necessários para concretizar um objetivo proposto. Para o desenvolvimento da tarefa, eles buscavam analisar quais conhecimentos prévios eram necessários (tanto em relação à utilização das tecnologias quanto para o fazer musical), identificar e se envolver com seus colegas, compartilhar escolhas e respeitar as renúncias necessárias para um trabalho colaborativo entre os pares.

Centradas sempre na perspectiva da aprendizagem colaborativa, as aulas eram pautadas nos interesses gerados pelos próprios alunos, e a estratégia adotada foi a de fomentar os conhecimentos tecnológicos paulatinamente, a partir da necessidade que aparecia na própria atividade. Assim, não houve uma "pausa" na aula para os alunos aprenderem a usar tal ferramenta ou produzirem tal atividade. A cada novo aplicativo, as informações gerais eram apresentadas, e os interesses fomentavam a

\footnotetext{
${ }^{4}$ As aulas são planejadas, estruturadas e desenvolvidas tendo como premissa a possibilidade de o aluno (re)discutir, problematizar e (re)construir suas próprias estratégias para consolidação da aprendizagem individual e coletiva.
} 
exploração, a explicação do uso dos materiais (digitais e musicais) e as necessidades de buscar coletivamente as informações necessárias para concluir as atividades propostas. Tal estratégia também foi adotada em relação aos conteúdos musicais.

Abordar esta postura em sala de aula contribuiu para a descentralização do papel do professor como o responsável pelo processo educativo e propiciou que a aprendizagem não se tornasse linear, nem em relação à música nem sobre a tecnologia empregada. Exatamente por isso o envolvimento dos alunos na construção da aprendizagem colaborativa tornou $o$ encaminhamento e o direcionamento das atividades de forma coesa, de acordo com as necessidades e dúvidas geradas no momento da tarefa. A proposta de não compartimentar o conhecimento musical e tecnológico proporcionou a produção do conhecimento de forma significativa ao aprendizado dos alunos. Assim, os papéis de todos se transformaram, pois todos possuíam responsabilidade pela aprendizagem individual e pelo sucesso coletivo no desenvolvimento das atividades desenvolvidas. Tal questão fundamenta os princípios propostos por Pierce e Gilles (2008) e Davidson e Major (2014) ao propor estratégias articuladas que respondam às demandas do desenvolvimento de todos no processo educativo.

A partir de então, os demais estudos (Cernev, 2016, 2017a, 2017b; Guerra; Cernev, 2017) visaram ampliar as relações em sala de aula por meio das tecnologias digitais, migrando para uma cibercultura em sala de aula, em que todos interagem com todos e todos aprendem com todos por meio de uma rede de colaboração. Ao aprender colaborativamente, os alunos são instigados constantemente a pensar sobre o fazer musical, priorizando 0 desenvolvimento do processo para chegar a um resultado final, às vezes em segundo plano. Os resultados destacam que a troca de percepções, o respeito pelas opiniões dos colegas, os conhecimentos, as preferências e ideias entre os alunos com a interação tecnológica abrem espaços para grupos colaborativos e para a produção de estratégias de aprendizagem.

Ao observar os resultados destes estudos, fica evidente que o desenvolvimento de uma aprendizagem colaborativa em que os alunos são autores e atores de seu próprio conhecimento é essencial para que eles possam se expressar musicalmente e se desenvolver de forma ativa na construção de estratégias que visam um conhecimento musical e colaborativo em sala de aula. O uso das tecnologias para o desenvolvimento da aprendizagem colaborativa nas aulas de música proporciona o que Lemos (2016) destaca sobre a importância do compartilhamento de novas experiências pedagógicas. Dessa forma, a colaboração numa perspectiva metodológica se mostrou uma proposta possivel de ser desenvolvida na educação básica (Cernev, 2015), no ensino superior (Cernev, 2016), como também na formação de professores (Guerra; Cernev, 2017). 


\section{CONSIDERAÇÕES FINAIS}

O desenvolvimento da aprendizagem colaborativa na perspectiva aqui discutida revela as potencialidades para que professores desenvolvam estratégias reais e possiveis para o uso das tecnologias digitais nas aulas de música de acordo com sua realidade pedagógica e com a realidade dos alunos. Embora alguns professores discutam as dificuldades de se ensinar frente à complexidade que envolve a evolução dos recursos tecnológicos, as vivências e os conhecimentos dos alunos perante a tecnologia podem ser contemplados e auxiliar o professor diante das suas próprias dificuldades tecnológicas. A aprendizagem colaborativa deve ser entendida como uma proposta metodológica em que alunos e professores constroem juntos e são igualmente responsáveis pela emissão e pela recepção de conhecimentos.

A aprendizagem colaborativa requer, assim, uma mudança no papel e no envolvimento do professor, uma vez que não caberá a ele delimitar tarefas, funções ou supervisionar o trabalho dos alunos. Nesta perspectiva, o professor sai do foco e está junto com os alunos na construção do conhecimento. Sua função neste processo é permitir e propiciar um espaço para que os alunos possam interagir uns com os outros e construir o conhecimento em conjunto.

O uso das tecnologias digitais contribui para um crescente aumento na variedade de opções e propostas metodológicas para o ensino de música. Toda essa tecnologia, amalgamada numa proposta metodológica colaborativa, pode contribuir consideravelmente para o conhecimento e para o desenvolvimento musical dos alunos e professores. Ao se associar o uso das tecnologias a uma proposta de aprendizagem colaborativa, abre-se a possibilidade para que alunos e professores possam criar grupos colaborativos capazes de transmitir informações, trocar experiências e aprender música em sala de aula.

Ao oferecer uma proposta metodológica descentralizada do papel do professor, coloca a atuação docente diante de duas questões diferentes, mas complementares: a aprendizagem dos alunos e a ação pedagógica dos professores. O interesse dos alunos em desenvolver um trabalho que, por utilizar as tecnologias em sala de aula, é muitas vezes considerado "novo" para sua aprendizagem e, ao mesmo tempo, a dificuldade de professores tanto em utilizar as tecnologias digitais para as práticas musicais quanto em sair do foco central como o único responsável pela aprendizagem em sala de aula ressaltam a importância deste estudo e a reflexão sobre esta temática na área da educação musical.

A realização deste estudo envolvendo o uso das tecnologias digitais e a colaboração, com todos os seus avanços e limites, permite apontar algumas considerações, em constante reflexão, mas férteis para suscitar questionamentos, abrir novos diálogos e fomentar outras discussões. Apesar de usarmos cotidianamente as tecnologias digitais, muitas instituições de ensino permanecem em grande parte baseadas no clássico modelo de 
produção do conhecimento: linear e tradicional. Urge, assim, a necessidade de criar novas possibilidades de articulação do ser, do saber e do fazer docente. Abre-se o foco para que a aprendizagem seja realizada de forma colaborativa, numa perspectiva calcada no respeito e na valorização dos nossos alunos.

Cabe especialmente lembrar que, como sujeitos sociais e culturais envolvidos com a formação de educadores e educandos, encontramo-nos profundamente implicados na responsabilidade pedagógica. Utilizar uma proposta metodológica que visa a aprendizagem colaborativa requer uma visão holística, refletindo sobre as práticas musicais, mediando interesses, valores e divergências, visando uma aprendizagem coesa e harmoniosa no contexto das tecnologias digitais para a educação musical.

\section{REFERENCIAS}

BARNES, Douglas. The value of exploratory talk. In: MERCER, N.; HODGKINSON, S. (Eds.). Exploring talk in school. Los Angeles: Sage, 2008. p. 1-15.

BARNES, Kassandra; MARATEO, Raymond C.; FERRIS, S. Pixy. Teaching and Learning with the Net Generation. Inovation, 2007. Disponivel em: <http:/ / www. innovateonline.info/index.php?view=article\&id=382>. Acesso em: 15 jul. 2017.

BOYD, Danah M.; ELLISON, Nicole. B. Social network sites: Definition, history, and scholarship. Journal of Computer-Mediated Communication, v. 13, n. 1, article 11, 2007.

BRNA, Paul. Modelos de Colaboração. Revista Brasileira de Informática na Educação, n. 3, [s.p.], 1998.

BRUFFE, Kenneth A. Collaborative Learning: higher education, Interdependence and the authority of knowledge. Baltimore: John Hopkins University Press, 1993.

BURNARD, Pamela. Reframing creativity and technology: promoting pedagogic change in music education. Journal of Music Technology and Education, v. 1, n. 1, p. 196-206, 2007.

CANGRO, Richard M. The effects of cooperative learning strategies on the music achievement of beginning instrumentalists. Tese (Doutorado) University of Hartford, Hartford, 2004.

CAPELLINI, Vera Lucia Messias F. Avaliação das possibilidades do ensino colaborativo para o processo de inclusão escolar do aluno com deficiência mental. Tese (Doutorado) - Universidade Federal de São Carlos, São Carlos, 2004. 
CERNEV, Francine K. Ensino, Aprendizagem e Formação: o uso das mídias sociais pelos licenciandos de música. In: CONFERÊNCIA LATINOAMERICANA DE EDUCAÇÃO MUSICAL, 11., 2017, Natal. Anais... Natal: ISME/ABEM, 2017a.

CERNEV, Francine K. O uso de blogs para Aprendizagem Musical no Ensino Superior: uma proposta de ensino híbrido com alunos da pedagogia. In: CONGRESSO NACIONAL DA ASSOCIAÇÃO BRASILEIRA DE EDUCAÇÃO MUSICAL, 23., 2017, Manaus. Anais... Manaus: ABEM, 2017b.

CERNEV, Francine K. Student collaboration and motivation using digital technologies: a case study in music education. In: ISME ABSTRACTS: ISME WORLD CONFERENCE, 32., 2016, Glasgow. Anais... Glasgow, UK, 2016. v. 1. p. $12-12$.

CERNEV, Francine K. Aprendizagem musical colaborativa mediada pelas tecnologias digitais: estratégias de aprendizagem e motivac,ão dos alunos. 2015. Tese (Doutorado em Música) - Instituto de Artes, Universidade Federal do Rio Grande do Sul, Porto Alegre, 2015.

CERNEV, Francine K. Aprendizagem Colaborativa mediada pelas Tecnologias Digitais: um estudo realizado nas aulas de música no contexto da educação básica. Hipertextus Revista Digital (UFPE), v. 10, p. 1-17, 2013.

CERNEV, Francine K; MALAGUTTI, Vania G. \#Escola \#Música \#Tecnologia: apreciar, executar e criar utilizando as tecnologias digitais em sala de aula. Música na Educação Básica, v. 7, p. 96-107, 2016.

CERNEV, Francine K.; RIBEIRO, Giann M.; CERESER, Cristina Mie I. O Uso das Tecnologias Digitais na Motivação para Aprender e Ensinar Música. In: CONGRESSO DA ASSOCIAÇÃO BRASILEIRA DE EDUCAÇÃO MUSICAL, 22., 2015, Natal. Anais... Natal: ABEM, 2015.

DAVIDSON, Niel; MAJOR, Claire H. Boundary crossings: cooperative learning, collaborative learning, and problem-based learning. Journal on Excellence in College Teaching, n. 25, v. 3\&4, p. 7-55, 2014.

DROTNER, Kirsten. Informal Learning and Digital Media: Perceptions, Practices and Perspectives. In: DROTNER, Kirsten; JENSEN, Hans Siggaard; SCHRØDER, Kim Christian (Eds.). Informal Learning and Digital Media. United Kingdon: Cambridge Scholars Publishing, 2008. p. 10-28.

FISHER, Mercedes; BAIRD, Derek. Online Learning Design that Fosters Student Support, Self-Regulation, and Retention. Campus-Wide Information Systems. The International Journal of Information and Learning Technology. v. 22, n. 2, 2005.

FLYNN, Pat; MESIBOV, Dom; VERMETTE, Paul J.; SMITH, R. Michael. Captivating classes with constructivism: practical strategies for pre-service 
and in-service teachers. New York: Institute for Learning Centered Education, 2013.

GIMENO SACRISTÁN, J. O currículo: os conteúdos do ensino ou uma análise prática. In: GIMENO SACRISTÃN, J.; PÉREZ GÓMEZ, A. I.

Compreender e transformar o ensino. 4. ed. Porto Alegre: ArtMed, 2000. Cap. 6, p. 119-148.

GOHN, Daniel M. A Internet em desenvolvimento: vivências digitais e interações sincronas no ensino a distância de instrumentos musicais. Revista da $A B E M$, v. 21, p. 25-34, 2013.

GOHN, Daniel M. Um breve olhar sobre a música nas comunidades virtuais. Revista da ABEM. v. 19, p. 113-119, 2008.

GREIFFENHAGEN, Christian. Making rounds: The routine work of the teacher during collaborative learning with computers. The International Journal of Computer-Supported Collaborative Learning (ijCSCL), v. 7, n. 1, p. $11-42,2012$.

GUERRA, Renata; CERNEV, Francine K. TecnoArte: uso das tecnologias digitais num curso de formação continuada com professores de Arte. In: CONGRESSO NACIONAL DA ASSOCIAÇÃO BRASILEIRA DE EDUCAÇÃO MUSICAL, 23., 2017, Manaus. Anais... Manaus: ABEM, 2017.

HARASIM, Linda. Learning theory and online technologies. New York: Taylor \& Francis, 2017.

HENTSCHKE, Liane; SCHNEIDER, Ana Francisca; CERNEV, Francine K. Digital Technology in Music Education: four case studies. In: ISME WORLD CONFERENCE ON MUSIC EDUCATION, 30., 2012, Thessaloniki. Music Paedeia: From Ancient Greek Philosophers Toward Global Music Communities. Thessaloniki, Anais... Thessaloniki, Greece, 2012.

HENTSCHKE, Liane; SCHNEIDER, Ana Francisca; CERNEV, Francine K. Tecnologia digital aplicada a educação musical: quatro estudos de caso. In: UJAT-CEDA ISME 2011 - PAN AMERICAN ISME REGIONAL CONFERENCE, 1.; NORTH AMERICAN ISME CONFERENCE, 1.; LATIN AMERICAN ISME CONFERENCE, 8., Anais... Tabasco, Mexico, 2011.

HILTZ, Roxanne. Collaborative Learning in Asynchronous Learning Networks: Building Learning Communities. WEB98, Orlando, Florida, Novembro. Disponivel em: <http://web.njit.edu/ hiltz/ collaborative_learning_in_asynch.htm>. Acesso em: 20 mar. 2017.

JENKINS, Herry. Fans, Bloggers and Gamers: essays on Participatory Culture. New York, London: New York University Press, 2006.

JOHNSON, David W.; JOHNSON, Roger T. Cooperation and the use of technology. In: JONASSEN, D. H. (Ed.). Handbook of research for educational 
communications and technology. New York: Simon and Schuster Macmillan, 1996. p. 1017-1044.

JOHNSON, David W.; JOHNSON, Roger T.; HOLUBEC, Edythe J. Cooperation in the Classroom - Revised edition. 8. ed. Edina, MN: Interaction Book Company, 2008.

KAGAN, Spencer; KAGAN; M. Kagan cooperative learning. San Clemente, CA: Kagan Publishing, 2009.

KOSCHMANN, Timothy. Dewey's contribution to the foundations of CSCL research. CONFERENCE ON COMPUTER SUPPORT FOR COLLABORATIVE LEARNING: FOUNDATIONS FOR A CSCL COMMUNITY, CSCL '02. Proceedings... Colorado: International Society of the Learning Sciences, 2002. p. 17-22.

LANEY, Robin; DOBBYN, Chris; XAMBÓ, Anna; SCHIROSA, Mattia; MIELL, Dorothy; LITTLETON, Karen; DALTON, Sheep. Issues and techniques for collaborative music making on multi-touch surfaces. In: SOUND AND MUSIC COMPUTING CONFERENCE, 7., Barcelona. 2010.

LEMOS, André. Cibercultura: tecnologia e vida social na cultura contemporânea. 8. ed. Porto Alegre: Sulina, 2016.

LI, M. P.; LAM, Bick Har. Cooperative learning: the Active Classroom. Hong Kong: The Hong Kong Institute of Education, 2013.

MATTAR, João. Games em educação: como os nativos digitais aprendem. São Paulo: Pearson Prentice Hall, 2010.

MORAN, José Manuel. Ensino e APRENDIZAGEM inovadores com tecnologias audiovisuais e telemáticas. In: MORAN, José Manuel; MASETTO, Marcos, BEHRENS, Marilda. Novas tecnologias e mediação pedagógica. 21. ed. São Paulo: Papirus, 2013.

MOURA, Risaelma de Jesus Arcanjo. Tecnologias da Informação e Comunicação na Educação Musical: caminhos para a abordagem colaborativa. In: CONGRESSO NACIONAL DA ASSOCIAÇÃO BRASILEIRA DE EDUCAÇÃO MUSICAL, 19., 2010, Goiânia. Anais... Goiânia, 2010.

MYERS, Jan (Ed.). Special edition: Cooperative College, Cooperative Education \& Research Conference. Journal of Cooperative Studies, v. 50, n. $1,2017$.

OTSUKA, Joice Lee. SAACI - Sistema de apoio à APRENDIZAGEM colaborativa na internet. Dissertação (Mestrado em Computação) Universidade Federal do Rio Grande do Sul, Porto Alegre, 1999.

PALINCSAR, A. Sullivan. Social constructivist perspectives on teaching and learning. Annual Review of Psychology, v. 49, p. 345-375, 1998. 
PANITZ, Theodore. Collaborative versus cooperative learning - a comparison of the two concepts which will help us understand the underlying nature of interactive learning. 1999. Disponivel em:

<http://www.capecod.net/ TPanitz/Tedspage>. Acesso em: 8 out. 2017.

PIERCE, Kathryn M.; GILLES, Carol. From exploratory talk to critical conversations. In: MERCER, N.; HODGKINSON, S. (Eds.). Exploring talk in school. Los Angeles: Sage, 2008. p. 37-53.

RODRIGUES, Denize F.; MACÊDO, Ivanildo I. de.; JOHANN, Maria Elizabeth P.; CUNHA, Neisa Maria M. da. Aspectos comportamentais da gestão de pessoas. 9. ed. Rio de Janeiro: FGV, 2011.

ROSCHELLE, Jeremy; TEASLEY, Stephanie. The construction of shared knowledge in collaborative problem solving. In: O'MALLEY, C. (Ed.). Computer-supported Collaborative Learning. New York: Springer-Verlag, 1995. p. 69-97.

SEDDON, Frederick A. Music e-learning environments: young people, composing and the internet. In: FINNEY, J.; BURNARD, P. (Eds.). Music Education with digital technology. London: Continuum Ed., 2007. p. 107116.

SERRES, Michel. Petite Poucette. Paris: Édition Le Pommier, 2012.

SILVA, Marco. Sala de aula interativa. São Paulo: Edições Loyola, 2010.

SLAVIN, Robert E. Cooperative learning: what makes groupwork work? In: DUMONT, H.; ISTANCE, D.; BENAVIDES, F. (Eds.). The Nature of Learning: using Research to Inspire Practice. Paris: OECD, 2010. p. 161-178.

STAHL, Gerry. Studying virtual math teams. New York: Springs, 2009.

TORRES, Patrícia L.; ALCÂNTARA, Paulo R.; IRALA, Esrom A. F. Grupos de Consenso: uma proposta de APRENDIZAGEM colaborativa para o processo de ensino APRENDIZAGEM. Revista Diálogo Educacional, v. 4, n. 13, p. 129$145,2004$.

VERDEJO, M. Felisa. Interaction and collaboration in distance learning through computer mediated technologies. In: LIAO, T. T. (Ed.). Advanced educational technology: research issues and future technologies. Berlin: Springer-Verlag, 1996. p. 77-88. 
Francine Kemmer Cernev é Doutora e Mestre em Música: Educação Musical - pelo Programa de Pós-Graduação em Música da Universidade Federal do Rio Grande do Sul (UFRGS). Pós graduada na área de educação infantil e séries iniciais, gestão de recursos humanos e regência musical. Licenciada em Música pela Universidade Estadual de Londrina (UEL) e bacharel em Administração de Empresas pela Universidade Norte do Paraná (UNOPAR). Professora do Departamento de Música da Universidade de Brasília (UNB) ministrando aulas na graduação (presencial, EAD) e pós-graduação. Atuou como professora colaboradora do Curso de Musica da Universidade Estadual de Londrina (2005-2008) e da Universidade Estadual de Maringá (2015-2017). Tem experiência na área de Artes, com ênfase em Música, atuando nos seguintes temas: Tecnologias Digitais Educacionais, Aprendizagem Colaborativa e Motivação para Aprender e Ensinar Música. 